\title{
An Integrated Fuzzy Goal Programming-Theory of Constraints Model for Production Planning and Optimization
}

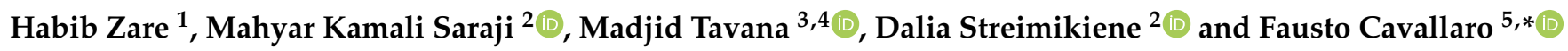 \\ 1 Faculty of Economics, Management and Accounting, Yazd University, Yazd 89158, Iran; Zarehabib@yazd.ac.ir \\ 2 Kaunas Faculty, Vilnius University, Muitines 8, LT-44280 Kaunas, Lithuania; \\ Mahyar.Kamali@knf.stud.vu.lt (M.K.S.); dalia.streimikiene@knf.vu.lt (D.S.) \\ 3 Distinguished Chair of Business Analytics, Business Systems and Analytics Department, La Salle University, \\ Philadelphia, PA 19141, USA; tavana@lasalle.edu \\ 4 Business Information Systems Department, Faculty of Business Administration and Economics, \\ University of Paderborn, 33098 Paderborn, Germany \\ 5 Department of Economics, University of Molise, 86100 Campobasso, Italy \\ * Correspondence: cavallaro@unimol.it
}

Citation: Zare, H.; Kamali Saraji, M.; Tavana, M.; Streimikiene, D.; Cavallaro, F. An Integrated Fuzzy Goal Programming-Theory of Constraints Model for Production Planning and Optimization. Sustainability 2021, 13, 12728. https://doi.org/10.3390/su132212728

Academic Editor: Peng-Yeng Yin

Received: 15 October 2021

Accepted: 13 November 2021

Published: 17 November 2021

Publisher's Note: MDPI stays neutral with regard to jurisdictional claims in published maps and institutional affiliations.

Copyright: (c) 2021 by the authors. Licensee MDPI, Basel, Switzerland. This article is an open access article distributed under the terms and conditions of the Creative Commons Attribution (CC BY) license (https:// creativecommons.org/licenses/by/ $4.0 /)$.

\begin{abstract}
Manufacturing companies are under constant pressure to optimize the economic sustainability of their production systems. Production planning and optimization is a well-established strategy for considering resource constraints and improving economic productivity. This study proposes an integrated fuzzy goal planning and the theory of constraints for production planning and optimization. To this end, a hybrid Delphi-Buckley method was used to identify the relevant goals and a paired matrix questionnaire was used to determine the fuzzy weights of the goals. Furthermore, a fuzzy bottleneck detection algorithm was used to deal with the bottlenecks. A case study in the cable industry is presented to demonstrate the applicability and exhibit the efficiency of the proposed model. The results indicate that production planning in the cable industry could experience less deviation, almost $11 \%$ less, from the goals by applying the fuzzy goal programming under the theory of constraints, compared to the traditional method or crisp-goal programming.
\end{abstract}

Keywords: production planning; optimization; fuzzy logic; TOC; sustainability; cable industry

\section{Introduction}

The cable industry comprises various products and manufacturing machines, different workstations throughout the process, and numerous limitations, such as each station's manufacturing and production pulleys [1]. Given the ever-increasing development of production systems and the increased mechanization of these systems, the need for production planning has increased, and the optimization of production systems has become very important [2]. There are many complexities and challenges in solving real-world production planning problems with traditional quantitative programming techniques [3]. Furthermore, production planners are often faced with difficult decisions when confronting various conflicting goals. Goal programming, a valuable branch of the multiple criteria decision-making (MCDM), can prioritize the goals and resolve the contradictions [4]. The advantage of goal planning in comparison to other programs is how it deals with real-world decision problems. Goal planning allows the decision-maker to combine environmental, organizational, and managerial factors in a model with several goals and priorities [5].

Decision-makers are faced with a complex and challenging decision to strictly initialize goal values in optimization problems, and this is the same for determining coefficients in the objective functions, constraints, and demand side. Some parameters may not have precise values; thus, an uncertainty assessment of these parameters is necessary [6]. Production planning is a concept that refers to a wide variety of planning techniques to maximize production and profit. Although many of these techniques are naturally computational, 
understanding concepts such as inventory control, capacity planning, and rolling horizons is very important for planners [7,8]. The goal of production planning is to estimate the amount of production of each commodity, the time needed to produce that quantity of a commodity, and the equipment needed to produce that commodity so that the relationship between economic factors for achieving a more significant profit and reducing the factors that cause customer dissatisfaction can be optimized [9]. For this reason, inventory and management and capacity planning are the significant production planning challenges facing managers today, especially in manufacturing facilities [10].

Production planning has become an interesting field over the years, motivating scholars to conduct research to deal with the many problems related to production planning. For instance, Wang et al. [11] applied a heuristic method to deal with order planning issues in the building sector in Vietnam. To this goal, they employed response surface methodology (RSM) to figure out the optimal value for system responses affected by three defined independent variables. However, this study applied the Theory of Constraints (TOC) to identify the variables and applied the fuzzy environment to deal with uncertainties. Rahman et al. [12] developed a theoretical framework to deal with the shortcomings in the conventional interval approach for production inventory. Although they applied a fuzzy environment to cope with uncertainties, they did not apply their framework to a specific real-life problem. One of the main contributions of the present study is the application of the optimization model to a real-life problem in the cable industry. Wang et al. [13] applied a heuristic method to deal with inventory management issues in Thailand. To this end, a computational model was developed to optimize the level of five independent factors and two main goals. However, the present study applies TOC to figure out more constraints and goals in production planning, including ten goals and nine constraints, making the present study more comprehensive and applicable than other studies.

Furthermore, Khan et al. [14] proposed a novel multi-objective model under the Intuitionistic and Neutrosophic environment to deal with multi-production planning problems. Their main contribution is to the theoretical part of the literature, while the present study proposes a more applicable model for optimization problems in production planning. Ali et al. [15] developed a multi-objective framework under an intuitionistic fuzzy environment to deal with inventory problems. The research is closely related to the present research as they applied fuzzy goal programming under a fuzzy environment; however, they tested their model using numerical examples. The present research managed to figure out real-life goals and constraints in the cable industry using TOC. Gupta et al. [16] developed a fuzzy goal programming model to deal with shipment problems. They considered many cases in their model, making their model comprehensive; nevertheless, they evaluated it using numerical examples. It is necessary to propose more applicable models in the production planning field, as in the present study.

Goal programming (GP) could be considered a practical and applicable approach to overcome the issues with linear models, introduced by Charnes and Cooper [17]. This method makes it possible to solve systems that have complicated and conflicting goals. In other words, goal planning is a way to achieve several goals simultaneously. The basis for doing so is that for each target, a certain number is formulated as a goal, and the target function is then formulated. Then, an answer will be found for minimizing the total weight of the deviation of each target relative to the goal set for the same target [18]. Narasimhan [19] integrated goal programing with fuzzy sets for the first time, while several scholars have shown their interest in fuzzy goal programming. For instance, Zhang et al. [20] developed a mixed-integer linear programming model to formulate the integrated optimization problem to minimize the total cost of production and warehouse operations. Mosadegh et al. [21] proposed a goal programming model to formulate the aggregate production planning problem mathematically, and then a fuzzy goal programming model was utilized to address the uncertainties encountered in real-world systems. Mehdizadeh et al. [22] used a fuzzy goal programming method to obtain appropriate production rates in regular and overtimes, inventory and shortage levels, workers' hiring 
and firing levels, and the quantities of the products that were subcontracted. Hall et al. [23] proposed an algorithm balance to tackle a planning problem with two planning periods. Kim and Glock [24] proposed a mathematical model to organize multiple parallel machines.

Goldratt and Cox [25] proposed the TOC, which significantly affects productivity improvement in manufacturing systems. On top of that, Rahman [26] mentioned that the TOC could be summarized as (i) "every system must have at least one constraint," and (ii) "the existence of constraints represents opportunities for improvement [27]." In this vein, several studies have employed the TOC to deal with production planning issues. For instance, Thürer et al. [28] examined the difference between drum-buffer-rope methods and TOC in workload control in shopping jobs. Akhoondi and Lotfi [29] combined TOC with metaheuristic algorithms to present a new model for production scheduling in the manufacturing industry. Manikas et al. [30] examined the differences between several production planning methods that included TOC. Golmohammadi [31] investigated the role of TOC in planning for shopping jobs. The working principle of the TOC consists of five focusing steps:

a. Identify the constraint

In this step, the constraint(s) is identified according to the TOC. When there is a limitation, the manager has fewer key points to control the system effectively, so the most crucial step is to identify the constraint.

b. Exploit the Constraint

Once the constraint is identified, you should use them to maximize the performance and ability to produce and sell the company.

c. Subordinate Everything Else to the Constraint

The constraint is the slowest or most limiting aspect of the system. Non-constraints should, therefore, provide the constraint with exactly enough resources to fully utilize the constraint.

d. Elevate the Constraint

Once the constraint's productivity has been maximized, the resources addressing the constraint must be expanded to increase the system's throughput. For example, we can elevate by adding more people or machines, training and mentoring, using better tools and faster machines, or switching to a different technology.

e. Prevent Inertia from Becoming the Constraint

Once a constraint has been elevated, a new constraint will emerge within the system, so we go back to the beginning.

As mentioned, production planning has a significant role in economic productivity; thus, the present study proposes an optimized fuzzy goal programming model under TOC principles to optimize the production process in the cable industry. Therefore, the main contributions of the presented study are:

- The application of a fuzzy goal programming model for the production planning problem under uncertainty in a cable manufacturing company;

- The Integration of the theory of constraints and goal programming into a unique model to support decision-making for production planning.

The remainder of this paper is organized as follows: Section 2 presents the research methodology in detail. Section 3 presents a case study to demonstrate the applicability of the proposed model. The results are presented in Section 4. Section 5 provides a discussion, and Section 6 provides the conclusion.

\section{Proposed Methodology}

As mentioned, the present research aims to optimize production processes regarding the four constraints, including capacity constraints, balance constraints, end-of-period inventories constraints, and order fulfillment constraints, presented in the following.

Capacity constraints 
The machine capacity is based on availability. Due to the change in production speed, speed $(\alpha)$ was added to the model based on the machine $(m)$. In the goal programming model, the deviation from the average production time was indicated with the variables $Y_{s m}^{-}(t)$ and $Y_{s m}^{+}(t)$ representing the inaction time and overtime work of different machines, respectively.

Balance constraints

To establish an effective relationship between the production lines, we needed a different set of constraints, namely the constraint of balance or the balance of steps. In this kind of constraint, the production of each product in each station is balanced by the amount needed to produce the product in the next stage. This balance is completed by considering the inventories remaining from the previous period, i.e., I $(t-1)$. Since part of the product is lost, the total production multiplies by the expression $\left(1-\mu_{S}\right)$. On the other hand, in some steps, the cables are shortened, and wires are lengthened by pulling or bending, and the difference will be considered using the parameter $\lambda$.

End-of-period inventories constraints

Products produced at different stages can be stored for use in later periods, but the number of products stored at the end of each period should not exceed a specific limit because of limited space. However, given the vast amount of company warehouses compared to the products produced, there is no limit to the final products. On the other hand, the pair of wires and stinging cables should be placed in a covered area to not suffer from exposure to air, sun, cold, etc. Cables with end-to-end intermediate casing can be placed in an open area outside the hall, so their constraint was considered goal related. In GP modeling, the variables $W^{-}(t)$ and $W^{+}(t)$ show, respectively, the inventory more than the specified capacity or less than the specified capacity.

Order fulfillment constraints

In the first part of this constraint, we expressed the production of fatty cables, considering their losses $(\mu)$, equal to the range of standard dimensions on the reel $\left(\theta_{1}\right)$, so that the number of reels could be obtained, and its constraint could be determined according to the order quantity.

The steps of the proposed optimization model are presented in the following, considering the four mentioned constraints.

Step 1: Problem formulation. The primary step in each methodology is the problem definition. After defining the problem precisely, some experts must be identified to evaluate the comprehensiveness of the problem definition and to determine the objectives and constraints after studying previous research and observations.

Step 2: Identification of the goals and system constraints. The experts' knowledge can be extracted through the Delphi method introduced in the late 1950s to acquire the most reliable consensus of experts' knowledge through an intensive questionnaire. The main reasons for choosing the Delphi method in this research were simplicity, anonymity, iteration, and controlled feedback, making it possible to find a complete view of the problem.

Step 3: Identification of the importance coefficients. To this end, the experts should prioritize goals using a paired-matrix questionnaire.

Step 4: Determination of the fuzzy weights. The Buckley method is used to obtain the fuzzy weights of the goals proposed by Buckley [32] to obtain the relative weight of the matrix of paired comparisons using the geometric mean method. The Buckley method could easily be applied to a fuzzy matrix to obtain the fuzzy weights that motivated this research to use the Buckley method to obtain goals.

Step 5: Identification of the bottlenecks. All bottlenecks are detected using the fuzzy product-mix bottleneck detection (FPMBD) algorithm (see Section 2.1).

Step 6: Model integration. As mentioned, a novel integrated model is proposed to optimize production processes by combining fuzzy goal programming and the theory of constraints (see Section 2.2).

Step 7: Model optimization. The LINGO software was applied to find an optimum solution. LINGO is a comprehensive tool designed to build and solve Linear, Nonlinear, 
and so on established by the LINDO system INC. The primary purpose of LINGO is to input a model formulation quickly, solve the formulation, and assess the formulation's correctness or appropriateness based on the solution.

Step 8: Model validation. What gives eligibility to a novel model is a validation step. To this end, the proposed model results can compare with other methods and models applied in the same process in which the proposed model was conducted to optimize it. The research methodology stages are shown in Figure 1.

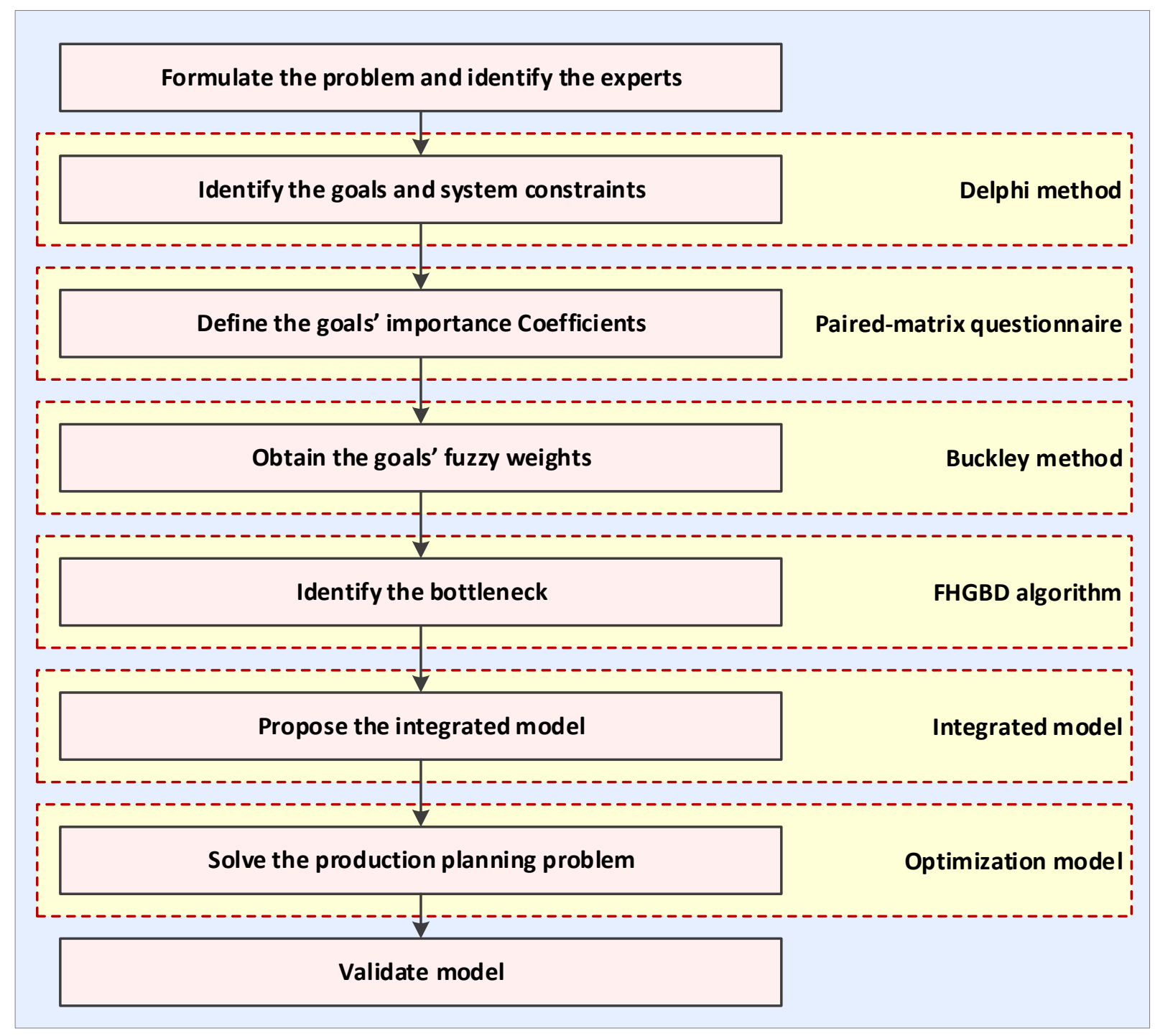

Figure 1. Proposed methodology.

\subsection{The FPMBD Algorithm}

The FPMBD algorithm proposed by Ghazinoori, et al. [33] is a hybrid algorithm for bottleneck detection in the system [34,35]. The FPMBD algorithm is based on the following assumptions:

- The processing time of each station is determined as a fuzzy number;

- The capacity of each station is determined as a fuzzy number;

- The capacity of all stations is related to the bottleneck station;

- The operational cost is a fixed cost.

The FPMBD algorithm is composed of three steps: 
Step 1: Calculate the sales potential using Equation (1) and multiply the processing time for each station by the demand to calculate the sales potential.

$$
Z_{q}(t) \cdot \widetilde{\alpha}_{q m}=\left(Z_{q}(t) \cdot \alpha_{q m_{1}}, Z_{q}(t) \cdot \alpha_{q m_{2}}, Z_{q}(t) \cdot \alpha_{q m_{3}}\right) q=1, \ldots, Q m=1, \ldots, M
$$

Step 2: Obtain the total processing time in each station by using Equation (2). This number shows the capacity of each station to supply the entire demand.

$$
\sum_{q=1}^{Q} Z_{q}(t) \cdot \widetilde{\alpha}_{q m}=\left(\sum_{q=1}^{Q} Z_{q}(t) \cdot Z_{q}(t) \cdot \alpha_{q m_{1}}, \sum_{q=1}^{Q} Z_{q}(t) \cdot Z_{q}(t) \cdot \alpha_{q m_{2}}, \sum_{q=1}^{Q} Z_{q}(t) \cdot Z_{q}(t) \cdot \alpha_{q m_{3}}\right)
$$

Step 3: Identify the bottleneck and non-bottleneck processes using Equations (3)-(5). If the relationships (3)-(5) are satisfied, the station is included in the non-bottleneck set; otherwise, the station is included in the bottleneck set.

$$
\begin{aligned}
& \sum_{q=1}^{Q} Z_{q}(t) \cdot Z_{q}(t) \cdot \alpha_{q m_{1}} \leq b_{m_{1}}(t) \\
& \sum_{q=1}^{Q} Z_{q}(t) \cdot Z_{q}(t) \cdot \alpha_{q m_{2}} \leq b_{m_{2}}(t) \\
& \sum_{q=1}^{Q} Z_{q}(t) \cdot Z_{q}(t) \cdot \alpha_{q m_{3}} \leq b_{m_{3}}(t)
\end{aligned}
$$

\subsection{Integrated Optimization Model}

This step integrates fuzzy goal planning and the TOC by introducing our objective function $(Z)$ and constraints. The objective function is composed of three components of order fulfillment, machine hours, and inventory capacity. We also consider four sets of constraints, including capacity constraints, balance constraints, end-of-period inventories constraints, and order fulfillment constraints as follows:

Objective function

$$
\operatorname{Min} Z=\widetilde{d}_{1} \sum_{q=1}^{Q} \sum_{i=1}^{J} \sum_{t=1}^{T}\left(Q_{q j}^{-}(t)\right)^{v}+\widetilde{d_{2}} \sum_{s=1}^{S} \sum_{m=1}^{M} \sum_{t=1}^{T}\left(Y_{s m}^{-}(t)\right)^{\beta}+\widetilde{d_{3}} \sum_{t=1}^{T} W^{+}(t)
$$

Capacity constraints

$$
\begin{aligned}
& \sum_{m=1}^{M}\left(\sum_{g=1}^{G} \widetilde{\alpha}_{g m} \cdot X_{g m}(t)+Y_{s m}^{-}(t)-Y_{s m}^{+}(t)\right)=\widetilde{H}_{s}(t) s=1, \forall t \\
& \sum_{m=1}^{M}\left(\sum_{c=1}^{C} \widetilde{\alpha}_{c m} \cdot X_{c m}(t)+Y_{s m}^{-}(t)-Y_{s m}^{+}(t)\right)=\widetilde{H}_{s}(t) s=2, \forall t \\
& \sum_{m=1}^{M}\left(\sum_{f=1}^{F} \widetilde{\alpha}_{f m} \cdot X_{f m}(t)+Y_{s m}^{-}(t)-Y_{s m}^{+}(t)\right)=\widetilde{H}_{s}(t) s=3, \forall t \\
& \sum_{m=1}^{M}\left(\sum_{h=1}^{H} \widetilde{\alpha}_{h m} \cdot X_{h m}(t)+Y_{s m}^{-}(t)-Y_{s m}^{+}(t)\right)=\widetilde{H}_{s}(t) s=4, \forall t \\
& \sum_{m=1}^{M}\left(\sum_{z=1}^{Z} \widetilde{\alpha}_{z m} \cdot X_{z m}(t)+Y_{s m}^{-}(t)-Y_{s m}^{+}(t)\right)=\widetilde{H}_{s}(t) s=5, \forall t \\
& \sum_{m=1}^{M}\left(\sum_{i=1}^{I} \widetilde{\alpha}_{i m} \cdot X_{i m}(t)+Y_{s m}^{-}(t)-Y_{s m}^{+}(t)\right)=\widetilde{H}_{s}(t) s=6, \forall t
\end{aligned}
$$




$$
\begin{aligned}
& \sum_{m=1}^{M}\left(\sum_{j=1}^{J} \widetilde{\alpha}_{j m} \cdot X_{j m}(t)+Y_{s m}^{-}(t)-Y_{s m}^{+}(t)\right)=\widetilde{H}_{s}(t) s=7, \forall t \\
& \sum_{m=1}^{M}\left(\sum_{k=1}^{K} \sum_{j=1}^{J} \widetilde{\alpha}_{k j m} \cdot X_{k j m}(t)+Y_{s m}^{+}(t)-Y_{s m}^{+}(t)\right)=\widetilde{H}_{s}(t) s=8, \forall t \\
& \sum_{m=1}^{M}\left(\sum_{l=1}^{L} \sum_{j=1}^{J} \widetilde{\alpha}_{l j m} \cdot X_{l j m}(t)+Y_{s m}^{+}(t)-Y_{s m}^{+}(t)\right)=\widetilde{H}_{s}(t) s=9, \forall t \\
& \sum_{m=1}^{M}\left(\sum_{r=1}^{R} \sum_{j=1}^{J} \widetilde{\alpha}_{r j m} \cdot X_{r j m}(t)+Y_{s m}^{+}(t)-Y_{s m}^{+}(t)\right)=\widetilde{H}_{s}(t) s=10, \forall t \\
& \sum_{m=1}^{M}\left(\sum_{q=1}^{Q} \sum_{j=1}^{J} \widetilde{\alpha}_{q j m} \cdot X_{q j m}(t)+Y_{s m}^{+}(t)-Y_{s m}^{+}(t)\right)=\widetilde{H}_{s}(t) s=11, \forall t \\
& Y_{s m}^{+}(t) \leq Y_{s m}^{\prime}(t)
\end{aligned}
$$

In stations such as intermediate stretching, extruder (insulator), shimmer, extruder (badge), the type of product produced at these stations is determined by the need for subsequent stations to determine the flow of semi-manufactured products in the production process. Thus, a $C$ product can be manufactured at an intermediate stretch station, which enters the Stringer station and partly to the Fine Extension Station. This process can occur on some of the stations, such as extruders (insulators) and shimmer. In other words, some of the products imported to the extruder station are past the Stringer Station and some other punchers. Therefore, the index $\mathrm{i}$ is divided concerning the imported product entered in the extruder station (insulator) in defining the station constraint.

Balance constraints

$$
\begin{gathered}
\sum_{m=m}^{M}\left(1-\widetilde{\gamma}_{s m}\right) \cdot X_{g m}(t)+I_{g}(t-1)=\sum_{m=m}^{M} \sum_{c=1}^{C} \lambda_{c m} \cdot X_{c m}(t) \\
\sum_{m=m}^{M}\left(1-\widetilde{\gamma}_{s m}\right) \cdot X_{c m}(t)+I_{c}(t-1)=\sum_{m=m}^{M} \sum_{f=1}^{F} \lambda_{f m} \cdot X_{f m}(t) \\
\sum_{m=m}^{M}\left(1-\widetilde{\gamma}_{s m}\right) \cdot X_{c m}(t)+I_{c}(t-1)=\sum_{m=m}^{M} \sum_{h=h}^{H} P_{h} \cdot \lambda_{h m} \cdot X_{h m}(t) \\
\sum_{m=m}^{M}\left(1-\widetilde{\gamma}_{s m}\right) \cdot X_{f m}(t)+I_{f}(t-1)=\sum_{m=m}^{M} \sum_{z=z}^{Z} P_{z} \cdot \lambda_{z m} \cdot X_{z m}(t) \\
\sum_{m=m}^{M}\left(1-\widetilde{\gamma}_{s m}\right) \cdot X_{z m}(t)+I_{z}(t-1)=\sum_{m=m}^{M} \sum_{i=1}^{I} X_{i m}(t) \\
\sum_{m=m}^{M}\left(1-\widetilde{\gamma}_{s m}\right) \cdot X_{h m}(t)+I_{h}(t-1)=\sum_{m=m}^{M} \sum_{i=1}^{I} X_{i m}(t) \\
\sum_{m=m}^{M}\left(1-\widetilde{\gamma}_{s m}\right) \cdot X_{i m}(t)+I_{i}(t-1)=\sum_{m=1}^{M} \sum_{j=1}^{J} P_{j} \cdot \lambda_{j m} \cdot X_{j m}(t) \\
\sum_{m=m}^{M}\left(1-\widetilde{\gamma}_{s m}\right) \cdot X_{i m}(t)+I_{i}(t-1)=\sum_{m=m}^{M} \sum_{q=q}^{Q} X_{q j m}(t) \\
\sum_{m=m}^{M}\left(1-\widetilde{\gamma}_{s m}\right) \cdot X_{j m}(t)+I_{j}(t-1)=\sum_{m=m}^{M} \sum_{k=1}^{K} X_{k j m}(t)
\end{gathered}
$$




$$
\begin{aligned}
& \sum_{m=m}^{M}\left(1-\widetilde{\gamma}_{s m}\right) \cdot X_{k j m}(t)+I_{k j}(t-1)=\sum_{m=1}^{M} \sum_{l=1}^{L} X_{l j m}(t) \\
& \sum_{m=m}^{M}\left(1-\widetilde{\gamma}_{s m}\right) \cdot X_{k j m}(t)+I_{k j}(t-1)=\sum_{m=1}^{M} \sum_{q=1}^{Q} X_{q j m}(t) \\
& \sum_{m=m}^{M}\left(1-\widetilde{\gamma}_{s m}\right) \cdot X_{k j m}(t)+I_{k j}(t-1)=\sum_{m=1}^{M} \sum_{r=1}^{R} X_{r j m}(t) \\
& \sum_{m=m}^{M}\left(1-\widetilde{\gamma}_{s m}\right) \cdot X_{l j m}(t)+I_{l j}(t-1)=\sum_{m=1}^{M} \sum_{q=q}^{Q} X_{q j m}(t) \\
& \sum_{m=m}^{M}\left(1-\widetilde{\gamma}_{s m}\right) \cdot X_{r j m}(t)+I_{r j}(t-1)=\sum_{m=1}^{M} \sum_{q=q}^{Q} X_{q j m}(t)
\end{aligned}
$$

End-of-period inventories constraints

$$
\begin{gathered}
\sum_{m=1}^{M} \sum_{g=1}^{G}\left(1-\widetilde{\gamma}_{s m}\right) \cdot X_{g m}(t)+\sum_{g=1}^{G} I_{g}(t-1) \leq W_{s}(t) s=1, \forall t \\
\sum_{m=1}^{M} \sum_{c=1}^{C}\left(1-\widetilde{\gamma}_{s m}\right) \cdot X_{c m}(t)+\sum_{c=1}^{C} I_{c}(t-1) \leq W_{s}(t) s=2, \forall t \\
\sum_{m=1}^{M} \sum_{f=1}^{F}\left(1-\widetilde{\gamma}_{s m}\right) \cdot X_{f m}(t)+\sum_{f=1}^{F} I_{f}(t-1) \leq W_{s}(t) s=3, \forall t \\
\sum_{m=1}^{M} \sum_{h=1}^{H}\left(1-\widetilde{\gamma}_{s m}\right) \cdot X_{h m}(t)+\sum_{h=1}^{H} I_{h}(t-1) \leq W_{s}(t) s=4, \forall t \\
\sum_{m=1}^{M} \sum_{z=1}^{Z}\left(1-\widetilde{\gamma}_{s m}\right) \cdot X_{z m}(t)+\sum_{z=1}^{Z} I_{z}(t-1) \leq W_{s}(t) s=5, \forall t \\
\sum_{m=1}^{M} \sum_{i=1}^{I}\left(1-\widetilde{\gamma}_{s m}\right) \cdot X_{i m}(t)+\sum_{i=1}^{I} I i(t-1) \leq W_{s}(t) s=6, \forall t \\
\sum_{m=1}^{M} \sum_{j=1}^{J}\left(1-\widetilde{\gamma}_{s m}\right) \cdot X_{j m}(t)+\sum_{j=1}^{J} I_{j}(t-1) \leq W_{s}(t) s=7, \forall t \\
\sum_{m=1}^{M} \sum_{j=1}^{J} \sum_{k=1}^{K}\left(1-\widetilde{\gamma}_{s m}\right) \cdot X_{k j m}(t)+\sum_{j=1}^{J} \sum_{k=1}^{K} I_{k j}(t-1)+W^{-}(t)-W^{+}(t)=W_{s}(t) s=8, \forall t \\
\sum_{m=1}^{M} \sum_{j=1}^{J} \sum_{l=1}^{L}\left(1-\widetilde{\gamma}_{s m}\right) \cdot X_{l j m}(t)+\sum_{j=1}^{J} \sum_{l=1}^{L} I_{l j}(t-1) \leq W_{s}(t) s=9, \forall t \\
\sum_{m=1}^{M} \sum_{j=1}^{J} \sum_{r=1}^{R}\left(1-\widetilde{\gamma}_{s m}\right) \cdot X_{r j m}(t)+\sum_{j=1}^{J} \sum_{r=1}^{R} I_{r j}(t-1) \leq W_{s}(t) s=10, \forall t
\end{gathered}
$$

Order fulfillment constraints

$$
\begin{gathered}
\sum_{m=1}^{M}\left(1-\widetilde{\gamma}_{s m}\right) \cdot X_{q j}+I_{q j}(t-1)=\theta_{q j} \cdot U_{q j}(t) \\
U_{q j}(t)-O_{q j}^{+}(t)+O_{q j}^{-}(t)=O_{q j}(t)
\end{gathered}
$$

All variables $\geq 0, U_{q j}(t) \in Z$ 


\section{Case Study}

A real-world problem from a cable production company is considered in this paper. There are sixteen stations, each with a specific capacity, in the Yazd Cable Company. The purpose of the model was to identify the bottlenecks using TOC to maximize capacity. According to the experts' opinions, it was decided to design the model in a way that the gas station could work with its maximum capacity and plan in such a way to face minimal inaction in bottlenecks. Moreover, with the request of the company's planning unit, the model was supposed to work so that the products that did not pass through bottlenecks would be given a higher priority in the order of construction. In other words, the priority of delivering products to customers would be, according to the company's experts, with products that do not cross the bottleneck station.

The related literature was reviewed to identify the problem and understand all influential factors, as shown in Table 1. Then, experts gathered to determine the objectives and constraints. The experts included managers and engineers, members of the board of directors. Also, they had at least ten years of work experience in the cable industry, and a Master's degree was the prerequisite for selecting the experts. It should be noted that the experts' opinions were asked through face-to-face interviews based on the Delphi method.

Table 1. Identified goals and constraints.

\begin{tabular}{|c|c|}
\hline Identified Goals & Author (s) and Year \\
\hline Launching Costs & $\begin{array}{c}\text { Jamalnia and Soukhakian [3], Camargo, et al. [36], Gramani, et al. [37], Baykasoglu } \\
\text { and Gocken [38], Belmokaddem and Mekidiche [39], Das, et al. [40] }\end{array}$ \\
\hline Final Inventory Maintenance Costs & $\begin{array}{c}\text { Zhang, Nishi, Turner, Oga and Li [20], Camargo, Mattiolli and Toledo [36], Gramani, } \\
\text { França and Arenales [37], Baykasoglu and Gocken [38], Leung and Chan [41], } \\
\text { Shi, et al. [42] }\end{array}$ \\
\hline Production Cycle time & Das, Baki and Li [40], Mehdi, et al. [43] \\
\hline Order Delay Costs & $\begin{array}{l}\text { Jamalnia and Soukhakian [3], Camargo, Mattiolli and Toledo [36], Gramani, França } \\
\text { and Arenales [37], Baykasoglu and Gocken [38], Belmokaddem and Mekidiche [39] }\end{array}$ \\
\hline Transfer Costs & $\begin{array}{c}\text { Jamalnia and Soukhakian [3], Kim and Glock [24], Camargo, Mattiolli and Toledo [36], } \\
\text { Belmokaddem and Mekidiche [39] } \\
\text { Jamalnia and Soukhakian [3], Gramani, França and Arenales [37], Baykasoglu and }\end{array}$ \\
\hline Human Resources Costs & $\begin{array}{c}\text { Gocken [38], Belmokaddem and Mekidiche [39], Leung and Chan [41], Shi, Zhang and } \\
\text { Sha [42] }\end{array}$ \\
\hline Raw Materials Maintenance Costs & Gramani, França and Arenales [37], Leung and Chan [41], Shi, Zhang and Sha [42] \\
\hline $\begin{array}{l}\text { Semi-manufactured product maintenance } \\
\qquad \text { costs }\end{array}$ & [20], Leung and Chan [41], Shi, Zhang and Sha [42] \\
\hline Inaction time of & Kim and Glock [24], Mehdi, Neng and Tongdan [43] \\
\hline Overtime Work of & Leung and Chan [41] \\
\hline Identified constraints & Author (s) and year \\
\hline Production Machine Capacity & $\begin{array}{c}\text { Jamalnia and Soukhakian [3], Hall, Posner and Potts [23], Camargo, Mattiolli and } \\
\text { Toledo [36], Gramani, França and Arenales [37], Baykasoglu and Gocken [38], } \\
\text { Belmokaddem and Mekidiche [39], Das, Baki and Li [40], Shi, Zhang and Sha [42], } \\
\text { Torabi, et al. [44] }\end{array}$ \\
\hline Product Demand Rate & $\begin{array}{l}\text { Gramani, França and Arenales [37], Baykasoglu and Gocken [38], Das, Baki and Li } \\
\text { [40], Shi, Zhang and Sha [42] }\end{array}$ \\
\hline Raw Materials & Zhang, Nishi, Turner, Oga and Li [20], Leung and Chan [41] \\
\hline Line Balance & $\begin{array}{l}\text { Hall, Posner and Potts [23], Camargo, Mattiolli and Toledo [36], Shi, Zhang and Sha } \\
\text { [42] }\end{array}$ \\
\hline Order Deadline & Camargo, Mattiolli and Toledo [36] \\
\hline Human Resources & $\begin{array}{c}\text { Jamalnia and Soukhakian [3], Baykasoglu and Gocken [38], Leung and Chan [41], Shi, } \\
\text { Zhang and Sha [42] }\end{array}$ \\
\hline Overtime Work of the Machines & $\begin{array}{c}\text { Hall, Posner and Potts [23], Kim and Glock [24], Das, Baki and Li [40], Torabi, Ebadian } \\
\text { and Tanha [44] }\end{array}$ \\
\hline Transfer & Kim and Glock [24], Mehdi, Neng and Tongdan [43] \\
\hline $\begin{array}{l}\text { Inventory Capacity (Semi-manufactured } \\
\text { Product) }\end{array}$ & $\begin{array}{l}\text { Jamalnia and Soukhakian [3], Camargo, Mattiolli and Toledo [36], Gramani, França } \\
\text { and Arenales [37], Baykasoglu and Gocken [38], Belmokaddem and Mekidiche [39], } \\
\text { Shi, Zhang and Sha [42], Torabi, Ebadian and Tanha [44] }\end{array}$ \\
\hline
\end{tabular}


The second step was the identification of the goals and system constraints (Table 2). According to the Delphi method, the experts gave a score (out of 10) to the considered goals and constraints using a questionnaire. The Cronbach's alpha of the used questionnaire was 0.87 , and after aggregating all questionnaires, the average Delphi Score was calculated to determine the appropriate goals and constraints for the Yazd cable company. Those goals and constraints with an average Delphi Score above 0.8 were chosen as the final goals and constraints.

Table 2. Delphi results for the goals and constraints.

\begin{tabular}{|c|c|c|c|c|c|}
\hline \multicolumn{6}{|c|}{ Average Delphi Scores of the Identified Final Factors to Identify Model Goals } \\
\hline Factor & Transfer Costs & Order Delay Costs & Production Cycle time & $\begin{array}{c}\text { Final Inventory } \\
\text { Maintenance Costs }\end{array}$ & Launching Costs \\
\hline Average & 5.82 & 9.81 & 6.16 & 3.18 & 5.18 \\
\hline Factor & $\begin{array}{c}\text { Overtime Work of the } \\
\text { Machines }\end{array}$ & $\begin{array}{l}\text { Inaction time of } \\
\text { the Machines }\end{array}$ & $\begin{array}{l}\text { Semi-manufactured } \\
\text { product maintenance } \\
\text { costs }\end{array}$ & $\begin{array}{c}\text { Raw Materials } \\
\text { Maintenance Costs }\end{array}$ & $\begin{array}{c}\text { Human Resources } \\
\text { Costs }\end{array}$ \\
\hline Average & 5.12 & 8.52 & 7.82 & 4.12 & 6.17 \\
\hline \multicolumn{6}{|c|}{ Average Delphi Scores of Identified Final Factors to Identify Model Constraints } \\
\hline Factor & Order Deadline & Line Balance & Raw Materials & $\begin{array}{c}\text { Product Demand } \\
\text { Rate }\end{array}$ & $\begin{array}{c}\text { Production } \\
\text { Machine Capacity }\end{array}$ \\
\hline Average & 10 & 10 & 4.48 & 8.15 & 10 \\
\hline Factor & $\begin{array}{c}\text { Inventory Capacity } \\
\text { (Semi-manufactured } \\
\text { Product) }\end{array}$ & Transfer & $\begin{array}{l}\text { Overtime Work of the } \\
\text { Machines }\end{array}$ & Human Resources & - \\
\hline Average & 8.45 & 6.28 & 8.15 & 5.81 & - \\
\hline
\end{tabular}

After identifying the goals, the importance coefficients of the goals were assigned, results are shown in Table 3, using a paired matrix questionnaire (Appendix A), and the fuzzy weight of goals was obtained by the Buckley method, the results of which are shown in Table 4. Afterward, all bottlenecks in Yazd cable company were identified using the FPMBD algorithm, and the proposed integrated model was applied regarding the goals and constraints in the Yazd cable company. After solving the integrated model by LINGO, the final step was model validation. To this end, the proposed method results were compared with the traditional solving method and a crisp solving model. In the traditional solving method, the amount of each product was determined by experts based on some information the marketing unit had gathered before. Besides, in this research, the proposed model results were compared with a crisp solving method to show the advantages of the fuzzy model in the field of production planning problems in which the information is characterized by indeterminacy and uncertainty.

Table 3. Triangular fuzzy numbers.

\begin{tabular}{cccc}
\hline Goals & $\mathbf{1}$ & $\mathbf{2}$ & $\mathbf{3}$ \\
\hline 1 & $(1,1,1)$ & $(5.75,7,8.25)$ & $(8.5,9.25,10)$ \\
2 & $(0.121,0.142,0.173)$ & $(1,1,1)$ & $(3.37,4.5,5.75)$ \\
3 & $(0.1,0.108,0.117)$ & $(0.173,0.222,0.296)$ & $(1,1,1)$ \\
\hline
\end{tabular}


Table 4. Weights obtained by Buckley's method.

\begin{tabular}{ccccccc}
\hline \multirow{2}{*}{ Goals } & \multicolumn{3}{c}{ Geometric Average } & \multicolumn{3}{c}{ Weights } \\
\cline { 2 - 7 } & $\mathbf{a}$ & $\mathbf{b}$ & $\mathbf{c}$ & $\mathbf{a}$ & $\mathbf{b}$ & $\mathbf{c}$ \\
\hline 1 & 3.6 & 3.96 & 4.28 & 0.64 & 0.78 & 0.93 \\
2 & 0.73 & 0.86 & 0.99 & 0.13 & 0.16 & 0.22 \\
3 & 0.26 & 0.287 & 0.32 & 0.05 & 0.06 & 0.07 \\
\hline
\end{tabular}

\section{Results}

As mentioned, the Delphi method was used to identify goals and constraints. The results are shown in Table 2.

Based on the results in Table 1, the goals of the mathematical model are:

- Fulfilling orders as much as possible;

- Maximizing work hours of machines;

- Minimizing inventory capacity allocated to middle-end products.

As explained in Section 3, a paired matrix was used to prioritize the goals, and the results are shown in Table 3. The Triangular Fuzzy Numbers (TFNs) were used since each variable is determined by the standard threshold; also, TFNs convey the attributed value objectively to reflect the decision-making information. This capability preserves the variables' taking value interval and emphasizes the possibility of a range of values inside it.

Besides, the Buckley method was used to obtain the fuzzy weights of the goals, and the results are shown in Table 4.

It is possible to distinguish bottlenecks at each station from other stations using the FPMBD algorithm. Table 5 shows the capacity of each station and the available capacity of each station with regards to the demand potential of each station for 60 days, all of which were extracted from the information in the company's engineering department under study. Regarding the relations in the third step, it was determined that "intermediate stretch" stations (Row 2) and "Stringer 7 string: (Row 5) were the bottlenecks in the production system.

Table 5. Station capacities.

\begin{tabular}{|c|c|c|c|c|c|c|c|}
\hline \multirow{2}{*}{ Row } & \multirow{2}{*}{ Station Name } & \multicolumn{3}{|c|}{ Total Available Time (min) } & \multicolumn{3}{|c|}{ Total Expected Processing Times (min) } \\
\hline & & a & b & c & a & $\mathbf{b}$ & c \\
\hline 1 & Rod pulling & 680,000 & 730,000 & 790,000 & 621,200 & 670,950 & 720,950 \\
\hline 2 & Intermediate Pulling & 798,000 & 850,000 & 908,000 & 812,850 & 920,120 & 980,390 \\
\hline 3 & Fine Pulling & 428,000 & 462,000 & 496,000 & 384,220 & 395,000 & 405,000 \\
\hline 4 & Stringer 61 string & 51,500 & 54,000 & 565,000 & 37,100 & 38,510 & 39,950 \\
\hline 5 & Stringer 7 string & 42,700 & 50,000 & 61,200 & 64,720 & 68,980 & 73,250 \\
\hline 6 & Puncher & 295,000 & 330,000 & 364,000 & 262,580 & 287,000 & 311,420 \\
\hline 7 & Extruder 90 Insulation & 164,250 & 198,000 & 231,750 & 162,800 & 165,000 & 167,200 \\
\hline 8 & Extruder 60 Insulation & 105,500 & 132,000 & 158,000 & 89,720 & 95,200 & 101,650 \\
\hline 9 & Extruder 90 Filter & 227,800 & 240,000 & 260,800 & 222,540 & 238,000 & 243,620 \\
\hline 10 & Tablature 7 string & 34,500 & 36,000 & 37,500 & 30,900 & 32,300 & 33,800 \\
\hline 11 & Tablature 19 string & 58,000 & 66,000 & 75,000 & 42,650 & 48,500 & 54,360 \\
\hline 12 & Cable & 13,150 & 15,000 & 17,000 & 6980 & 7520 & 8060 \\
\hline 13 & Screen & 120,000 & 135,000 & 150,000 & 83,200 & 85,000 & 86,820 \\
\hline 14 & Armoring & 129,000 & 135,000 & 150,000 & 125,000 & 128,040 & 132,520 \\
\hline 15 & Extruder 100 & 255,500 & 264,000 & 272,000 & 212,500 & 238,450 & 264,400 \\
\hline 16 & Extruder 120 & 412,850 & 450,000 & 487,000 & 365,500 & 399,850 & 434,200 \\
\hline
\end{tabular}

According to the factory management decision, only solutions with a value of $\beta$ greater than 0.6 were investigated. As mentioned, the Lingo 11 was used to solve the proposed model, presented in Table 6 . 
Table 6. Acceptable efficient answers at $\beta$-level.

\begin{tabular}{cc}
\hline$\beta$ & $\tilde{Z}^{0}=(\beta)$ \\
\hline 0.7 & $(268,120,283,011,320,821)$ \\
\hline 0.8 & $(268,280,283,157,320,890)$ \\
\hline 0.9 & $(268,431,283,297,321,051)$ \\
\hline 1 & $(273,376,289,221,325,980)$ \\
\hline
\end{tabular}

Therefore, according to the decision of the management, the proper membership function for the objective function is defined as follows:

$$
\mu_{\widetilde{G}}(Z)=\left\{\begin{array}{cc}
1 & Z \leq 268120 \\
\frac{325980-z}{325980-268120} & 268120 \leq Z \leq 325980 \\
0 & Z \leq 325980
\end{array}\right.
$$

Moreover, according to the method presented by Jimenez et al. (2007), the compatibility index of each solution is equal to:

$$
\begin{aligned}
K_{\widetilde{G}}\left(Z^{0}(0.7)\right) & =0.64 \\
K_{\widetilde{G}}\left(Z^{0}(0.8)\right) & =0.64 \\
K_{\widetilde{G}}\left(Z^{0}(0.9)\right) & =0.63 \\
K_{\widetilde{G}}\left(Z^{0}(1)\right) & =0.54
\end{aligned}
$$

and the degree of membership of any optimal solution with the utility of $\beta$ is equal to:

$$
\begin{gathered}
\mu_{\widetilde{D}}\left(Z^{0}(0.7)\right)=0.64 * 0.7=0.45 \\
\mu_{\widetilde{D}}\left(Z^{0}(0.8)\right)=0.64 * 0.8=0.51 \\
\mu_{\widetilde{D}}\left(Z^{0}(0.9)\right)=0.63 * 0.9=0.57 \\
\mu_{\widetilde{D}}\left(Z^{0}(1)\right)=0.54 * 1=0.54
\end{gathered}
$$

Regarding the compatibility indices, it is shown that the problem for the value of $\beta=0.9$ had the highest degree of membership rate of 0.57 , and for decision making, it is necessary to use the results which, in terms of the acceptance level, were practically acceptable responses. The expected value of $Z^{0}(0.9)$ from the proposed method by Jimenez et al. (2007) is:

$$
E V\left(\widetilde{Z}^{0}(0.9)\right)=\frac{1}{4}(268431+(2 * 283297)+321051)=289019
$$

\section{Discussion}

A comparative analysis was conducted to evaluate the performance of the proposed methodology compared to the traditional method and crisp-GP. Table 7 shows the results of the comparative analysis, confirming that the model proposed in this study achieved less adverse deviations than the traditional methods used by the company. Although the definite goal planning model has fewer unfavorable deviations than the fuzzy goal planning, it should be noted that we dealt with humans and machines in a real-world environment where crisp data were not readily available, and fuzzy models are needed to 
cope with this reality [45]. On top of that, the model's validity was confirmed by meeting with the company's experts and reviewing the results.

Table 7. Comparative results.

\begin{tabular}{cccc}
\hline Method Explanation & Traditional & Crisp Goal Planning & Fuzzy Goal Planning \\
\hline The value of the objective function $(z)$ & 324,280 & 279,892 & 289,019 \\
\hline
\end{tabular}

According to the results, the present study has proposed a more comprehensive and applicable fuzzy goal programming model compared to other studies, such as Wang, Nguyen and Dang [11] and Wang, Dang and Nguyen [13] since not only did the present study apply the fuzzy environment to deal with uncertainties but also the present study integrated the TOC to figure out goals and constraints in the cable industry. On top of that, the present study applied the integrated model to deal with a real*life problem in a cable company in Yazd, Iran, making the proposed model more trustworthy and practical compared to other studies whose main contribution was extending the theoretical part of literature, such as Ali, Gupta and Ahmed [15] and Gupta, Ali and Chaudhary [16].

\section{Conclusions}

The present research investigated whether the fuzzy goal programming model and the theory of constraints could be a suitable model for planning the production of a wire and cable company. The results indicated that applying the proposed model led to an $11 \%$ reduction in the deviation from the company's goals. The proposed model provided an efficient and flexible paradigm for determining the optimal production for each machine, the amount of overtime needed, and the amount of slack time. The concepts of the theory of constraints have helped us identify the constraints and bottlenecks in the system and, at the same time, allowed us to adjust the production quantities according to the capacity of the bottleneck station for each machine. The proposed model will produce products that do not cross the bottleneck stations with a higher priority.

Managerial implications could be: (1) cable companies could boost the possibility of utilizing resources according to the capacity of machines using the proposed method; (2) it would be possible to plan proper maintenance and more appropriate workforce planning through an estimation of the idle hours for the machine; and (3) the proposed model could enable companies to reduce the time required for coordination and collaboration problems, especially in working days off.

Furthermore, the present research has faced some limitations: (1) developing the mathematical model was time-consuming and required a great deal of care and (2) interviews with experts were also time-consuming since they did not have any information about the Delphi method, fuzzy environment, and designed questionnaires. For future research, the proposed model could be combined with metaheuristic algorithms, such as Genetic algorithms for optimization. On top of that, it is possible to apply system dynamics and compare the results with the proposed methodology.

Author Contributions: Conceptualization, H.Z. and M.K.S.; methodology, H.Z. and M.K.S.; software, H.Z.; validation, D.S., M.T. and F.C.; formal analysis, H.Z.; investigation, H.Z.; resources, M.K.S.; data curation, M.K.S.; writing-original draft preparation, M.K.S.; writing-review and editing, H.Z.; visualization, M.K.S.; supervision, D.S., M.T. and F.C.; project administration, D.S.; funding acquisition, F.C. All authors have read and agreed to the published version of the manuscript.

Funding: This research received no external funding.

Institutional Review Board Statement: Not applicable.

Informed Consent Statement: Not applicable.

Data Availability Statement: Not applicable.

Conflicts of Interest: The authors declare no conflict of interest. 


\section{Appendix A}

Table A1. Paired comparison questionnaire for the prioritization of goals.

\section{Goals}

Goal 1: Fulfilling orders as much as possible

Goal 2: Minimizing inaction hours of the machines

Goal 3: Minimizing the over-the-capacity medium-wrapped cable with armor and screen saver stock

\section{Comparison Parameters}

\begin{tabular}{|c|c|c|c|c|c|c|}
\hline $\begin{array}{l}\text { Exactly X times } \\
\text { more important }\end{array}$ & $\begin{array}{l}\text { Exactly X times } \\
\text { less important }\end{array}$ & $\begin{array}{c}\text { Between } \mathrm{Y} \text { and } \\
\mathrm{Z} \text { times less } \\
\text { important }\end{array}$ & $\begin{array}{c}\text { Between } \mathrm{Y} \text { and } \\
\mathrm{Z} \text { times more } \\
\text { important }\end{array}$ & $\begin{array}{l}\text { About } X \text { times } \\
\text { less important }\end{array}$ & $\begin{array}{l}\text { About } X \text { times } \\
\text { more important }\end{array}$ & About equal \\
\hline
\end{tabular}

Note: $\mathrm{X}, \mathrm{Y}$ and $\mathrm{Z}$ are numbers between 1 and 9.

\section{Paired comparison table}

\begin{tabular}{ccc}
\hline Goals & 1 & 2 \\
\hline 1 & \\
\hline 2 & \\
\hline 3 & \\
\hline
\end{tabular}

\section{References}

1. Niroomand, S.; Vizvari, B. Exact mathematical formulations and metaheuristic algorithms for production cost minimization: A case study of the cable industry. Int. Trans. Oper. Res. 2015, 22, 519-544. [CrossRef]

2. Zgajnar, J. Optimal Allocation of Production Resources under Uncertainty: Application of the Muliticriteria Approach. Agric. Econ. 2016, 62, 556-565.

3. Jamalnia, A.; Soukhakian, M.A. A hybrid fuzzy goal programming approach with different goal priorities to aggregate production planning. Comput. Ind. Eng. 2009, 56, 1474-1486. [CrossRef]

4. Hassan, N.; Pazil, A.H.M.; Idris, N.S.; Razman, N.F. A goal programming model for bakery production. Adv. Environ. Biol. 2013, 7, 187-190.

5. Bhargava, A.K.; Singh, S.R.; Bansal, D. Production planning using fuzzy meta-goal programming model. Indian J. Sci. Technol. 2015, 8, 1-9. [CrossRef]

6. Saraji, M.K.; Mardani, A.; Köppen, M.; Mishra, A.R.; Rani, P. An extended hesitant fuzzy set using SWARA-MULTIMOORA approach to adapt online education for the control of the pandemic spread of COVID-19 in higher education institutions. Artif. Intell. Rev. 2021, 1-26. [CrossRef] [PubMed]

7. De Sampaio, R.J.B.; Wollmann, R.R.G.; Vieira, P.F.G. A flexible production planning for rolling-horizons. Int. J. Prod. Econ. 2017, 190, 31-36. [CrossRef]

8. Pooya, A.; Pakdaman, M. Analysing the solution of production-inventory optimal control systems by neural networks. RAIROOper. Res. 2017, 51, 577-590. [CrossRef]

9. Lalami, I.; Frein, Y.; Gayon, J.-P. Production planning in automotive powertrain plants: A case study. Int. J. Prod. Res. 2017, 55, 5378-5393. [CrossRef]

10. Chapman, S.N. The Fundamentals of Production Planning and Control; Pearson/Prentice Hall: Upper Saddle River, NJ, USA, 2006.

11. Wang, C.-N.; Nguyen, N.-A.-T.; Dang, T.-T. Solving Order Planning Problem Using a Heuristic Approach: The Case in a Building Material Distributor. Appl. Sci. 2020, 10, 8959. [CrossRef]

12. Rahman, M.S.; Shaikh, A.A.; Ali, I.; Bhunia, A.K.; Fügenschuh, A. A Theoretical Framework for Optimality Conditions of Nonlinear Type-2 Interval-Valued Unconstrained and Constrained Optimization Problems Using Type-2 Interval Order Relations. Mathematics 2021, 9, 908. [CrossRef]

13. Wang, C.-N.; Dang, T.-T.; Nguyen, N.-A.-T. A computational model for determining levels of factors in inventory management using response surface methodology. Mathematics 2020, 8, 1210. [CrossRef]

14. Khan, M.F.; Haq, A.; Ahmed, A.; Ali, I. Multiobjective Multi-Product Production Planning Problem Using Intuitionistic and Neutrosophic Fuzzy Programming. IEEE Access 2021, 9, 37466-37486. [CrossRef]

15. Ali, I.; Gupta, S.; Ahmed, A. Multi-objective linear fractional inventory problem under intuitionistic fuzzy environment. Int. J. Syst. Assur. Eng. Manag. 2019, 10, 173-189. [CrossRef]

16. Gupta, S.; Ali, I.; Chaudhary, S. Multi-objective capacitated transportation: A problem of parameters estimation, goodness of fit and optimization. Granul. Comput. 2020, 5, 119-134. [CrossRef]

17. Charnes, A.; Cooper, W.W. Management Models and Industrial Applications of Linear Programming; Wiley: Hoboken, NJ, USA, 1967. 
18. Huang, Z.S.; Yu, H.; Chu, X.Y.; Peng, Z.W. A goal programming based model system for community energy plan. Energy 2017, 134, 893-901. [CrossRef]

19. Narasimhan, R. Goal programming in a fuzzy environment. Decis. Sci. 1980, 11, 325-336. [CrossRef]

20. Zhang, G.; Nishi, T.; Turner, S.D.O.; Oga, K.; Li, X. An integrated strategy for a production planning and warehouse layout problem: Modeling and solution approaches. Omega 2017, 68, 85-94. [CrossRef]

21. Mosadegh, H.; Khakbazan, E.; Salmasnia, A.; Mokhtari, H. A fuzzy multi-objective goal programming model for solving an aggregate production planning problem with uncertainty. Int. J. Inf. Decis. Sci. 2017, 9, 97-115. [CrossRef]

22. Mehdizadeh, E.; Niaki, S.T.A.; Hemati, M. A bi-objective aggregate production planning problem with learning effect and machine deterioration: Modeling and solution. Comput. Oper. Res. 2018, 91, 21-36. [CrossRef]

23. Hall, N.G.; Posner, M.E.; Potts, C.N. Online production planning to maximize the number of on-time orders. Ann. Oper. Res. 2018, 1-21. [CrossRef]

24. Kim, T.; Glock, C.H. Production planning for a two-stage production system with multiple parallel machines and variable production rates. Int. J. Prod. Econ. 2018, 196, 284-292. [CrossRef]

25. Goldratt, E.M.; Cox, J. The Goal: A Process of Ongoing Improvement; Routledge: Oxfordshire, UK, 1984.

26. Rahman, S.U. Theory of constraints: A review of the philosophy and its applications. Int. J. Oper. Prod. Manag. 1998. [CrossRef]

27. Wu, K.; Zheng, M.; Shen, Y. A generalization of the Theory of Constraints: Choosing the optimal improvement option with consideration of variability and costs. IISE Trans. 2020, 52, 276-287. [CrossRef]

28. Thürer, M.; Stevenson, M.; Silva, C.; Qu, T. Drum-buffer-rope and workload control in High-variety flow and job shops with bottlenecks: An assessment by simulation. Int. J. Prod. Econ. 2017, 188, 116-127. [CrossRef]

29. Akhoondi, F.; Lotfi, M. A heuristic algorithm for master production scheduling problem with controllable processing times and scenario-based demands. Int. J. Prod. Res. 2016, 54, 3659-3676. [CrossRef]

30. Manikas, A.; Gupta, M.; Boyd, L. Experiential exercises with four production planning and control systems. Int. J. Prod. Res. 2015, 53, 4206-4217. [CrossRef]

31. Golmohammadi, D. A study of scheduling under the theory of constraints. Int. J. Prod. Econ. 2015, 165, 38-50. [CrossRef]

32. Buckley, J.J. Fuzzy hierarchical analysis. Fuzzy Sets Syst. 1985, 17, 233-247. [CrossRef]

33. Ghazinoori, S.S.; Sadeghian, R.; Samouei, P. Comparing of utilizing “theory of constraints' versus fuzzy linear programming in fuzzy product-mix problems. Int. J. Ind. Eng. Prod. Manag. 2010, 21, 1-10.

34. Rani, P.; Mishra, A.R.; Krishankumar, R.; Mardani, A.; Cavallaro, F.; Soundarapandian Ravichandran, K.; Balasubramanian, K. Hesitant Fuzzy SWARA-Complex Proportional Assessment Approach for Sustainable Supplier Selection (HF-SWARA-COPRAS). Symmetry 2020, 12, 1152. [CrossRef]

35. Ghazinoory, S.; Fattahi, P.; Samouei, P. A hybrid FRTOC-SA algorithm for product mix problems with fuzzy processing time and capacity. Int. J. Adv. Manuf. Technol. 2013, 65, 1363-1370. [CrossRef]

36. Camargo, V.C.; Mattiolli, L.; Toledo, F.M. A knapsack problem as a tool to solve the production planning problem in small foundries. Comput. Oper. Res. 2012, 39, 86-92. [CrossRef]

37. Gramani, M.C.N.; França, P.M.; Arenales, M.N. A linear optimization approach to the combined production planning model. J. Frankl. Inst. 2011, 348, 1523-1536. [CrossRef]

38. Baykasoglu, A.; Gocken, T. Multi-objective aggregate production planning with fuzzy parameters. Adv. Eng. Softw. 2010, 41, 1124-1131. [CrossRef]

39. Belmokaddem, M.; Mekidiche, M. Application of a Fuzzy Goal Programming Approach with Different Importance and Priorities to Aggregate Production Planning. J. Appl. Quant. Methods 2009, 4, 317-331.

40. Das, K.; Baki, M.F.; Li, X. Optimization of operation and changeover time for production planning and scheduling in a flexible manufacturing system. Comput. Ind. Eng. 2009, 56, 283-293. [CrossRef]

41. Leung, S.C.; Chan, S.S. A goal programming model for aggregate production planning with resource utilization constraint. Comput. Ind. Eng. 2009, 56, 1053-1064. [CrossRef]

42. Shi, J.; Zhang, G.; Sha, J. Optimal production planning for a multi-product closed loop system with uncertain demand and return Comput. Oper. Res. 2011, 38, 641-650. [CrossRef]

43. Mehdi, G.; Neng, F.; Tongdan, J. Multistage Stochastic Optimization for Production-Inventory Planning with Intermittent Renewable Energy. Prod. Oper. Manag. 2017, 26, 409-425. [CrossRef]

44. Torabi, S.A.; Ebadian, M.; Tanha, R. Fuzzy hierarchical production planning (with a case study). Fuzzy Sets Syst. 2010, 161, 1511-1529. [CrossRef]

45. Yan, Q.; Qin, G.; Zhang, M.; Li, W.; Chen, L. Research on Power Customer Comprehensive Evaluation and Service Strategy Based on Fuzzy Theory and TOPSIS in Opening Electricity Market. Transform. Bus. Econ. 2020, 2, 199-219. 